Pacific Journal of Mathematics

THE DIMENSION OF INTERSECTIONS OF CONVEX SET 


\section{THE DIMENSION OF INTERSECTIONS OF CONVEX SETS}

\section{BRANKo GRÜNBAUM}

1. The following problem was raised by V. Klee in a seminar on convex sets :

How are the assumptions of Helly's [5] theorem on intersections of convex sets to be modified in order to guarantee that the intersection of all the members of a finite family of convex sets in $E^{n}$ be of dimension at least $k$ ?

In this note we shall prove the following variant of Helly's theorem :

THEOREM. Let $k$ and $n, 0 \leqq k \leqq n$, be integers, and let $h(n, k)$ be the least integer rendering true the following statement:

For every finite family $\mathscr{K}$ of convex sets in $E^{n}$, containing at least $h(n, k)$ members, the intersection $I \mathscr{K}$ of all members of $\mathscr{K}$ has dimension $\operatorname{dim} \Pi \mathscr{K}$ at least $k$ provided the intersection of every $h(n, k)$ members of $\mathscr{K}$ is of dimension $k$ at least.

Then

$$
\begin{aligned}
& \text { (i) } h(n, 0)=n+1 \\
& \text { (ii) } h(n, 1)=2 n \\
& \text { (iii) } h(n, k)=2 n-k \text { for } 1<k<n \\
& \text { (iv) } h(n, n)=n+1 .
\end{aligned}
$$

Proof. Essentially, only the assertion (iii) is new. The first statement, $h(n, 0)=n+1$, is Helly's well-known theorem [5]. The assertion $h(n, n)=n+1$ is a theorem due to Vincensini [14], generalized by the following result of Klee [9] (which, in turn, follows easily from Helly's theorem): If $\mathscr{K}$ is a finite family of convex sets (or an infinite family of compact convex sets) in $E^{n}$ and if $C$ is a convex set such that for every $n+1$ members of $\mathscr{K}$ there exists a translate of $C$ contained in their intersection, then a suitable translate of $C$ is contained in $\Pi \mathscr{K}$.

The statement $h(n, 1)=2 n$, or facts equivalent to it, have been proved many times in a different terminology (Steinitz's [13] "irreducible all-sided families of rays", Dines-McCoy's [2] theorem on intersections of half-spaces through the origin (see also [11]); Gustin's [4] variant of Carathéodory's theorem; Robinson's [12] theorem on intersections of spherical convex sets). To derive (ii) from, e.g., the theorem of DinesMcCoy ("A family of closed half-spaces in $E^{n}$, each containing the origin in its boundary, has a common point different from 0 provided this is true for every $2 n$-membered subfamily") we observe first that it

Received December 29, 1960, and in revised form March 27, 1961. 
is sufficient to prove the theorem for families of polyhedra. (In each intersection of $h(n, k)$ members of the given family we choose an arbitrary point; each of the original sets is replaced by the convex hull of the (finitely many) chosen points belonging to it. See [11] for a more elaborate discussion of this procedure.) Next, assuming that the intersection of all the polyhedra $K \in \mathscr{K}$ (nonempty by Helly's theorem) consists of one point only (which we take as the origin 0), we may assume (because of (iv)) that 0 belongs to the boundary of each $K \in \mathscr{K}$. Replacing $\mathscr{K}$ by the family $\mathscr{H}$ of all closed half-spaces which contain some $K \in \mathscr{K}$ and have 0 in their boundary, it follows from the theorem of Dines-McCoy that the intersection of some $2 n$ members of $\mathscr{H}$ is the single point 0 ; the intersection of the $2 n$ or less members of $\mathscr{K}$ contained respectively in these members of $\mathscr{H}$ is then a fortiori reduced to 0 .

Before proceeding to prove (iii), we shall establish a few auxiliary results, which are also of some independent interest.

2. A subset of the $n-1$ dimensional sphere $S^{n-1}=\left\{x \in E^{n}:\|x\|=1\right\}$ is called convex if and only if it is the intersection of closed hemispheres. (In particular, a pair of antipodal points, or any "great $S^{k}$ " for $k \leqq n-1$, is a convex set). Sets "convex" in this sense have been studied, e.g., by Favard [3] and Robinson [12]; in some connections other definitions of spherically convex sets seem to be more appropriate (see, e.g. Horn [7]).

Lemma 1. If $\mathscr{C}$ is a finite family of convex subsets of $S^{n}$ such that the intersection of each $n+1$ members of $\mathscr{C}$ has a nonempty interior and such that $\Pi \mathscr{C} \neq \varnothing$, then Int $\Pi \mathscr{C} \neq \varnothing$.

Proof. Let $P \in \Pi^{\mathcal{C}}$ and let $H$ be the open hemisphere of $S^{n} \subset E^{n+1}$ centered at $P$. Project $H$ centrally onto the $E^{n}$ tangent to $S^{n}$ at $P$. Let $C^{\prime} \subset E^{n}$ be the projection of $H \cap C$ for $C \in \mathscr{C}$. Then the intersection of each $n+1$ of the sets $C$ has a nonempty interior and therefore, by the theorem of Vincensini [14] mentioned before, Int $\cap C^{\prime} \neq \varnothing$. This obviously implies the assertion of the lemma, Int $\Pi \mathscr{C} \neq \varnothing$.

Lemma 2. If $C \subset S^{n}$ is convex, Int $C \neq \varnothing$ and $C \neq S^{n}$, then $C$ is contractible (to any point in its interior).

Proof. If $P_{0} \in$ Int $C$, each point $P$ of $C$ is at a spherical distance $<\pi$ from $P_{0}$; therefore the smaller arc of the great circle joining $P_{0}$ and $P$ is contained in $C$.

REMARK. In the terminology of Helly [6], each convex set $C \subset S^{n}$, 
with nonempty interior and different from $S^{n}$, is a "cell". In the proof of the next lemma we shall use the following topological theorem of Helly [6] (see [1] for a similar result): "If a family of cells is given in $E^{n}$, such that the intersection of each $n$ or less of them is a cell, and the intersection of each $n+1$ nonempty, then the intersection of all the members of the family is nonempty."

Lemma 3. Let $\mathscr{C}$ be a finite family of convex subsets of $S^{n}$, such that the intersection of every $n+1$ members of $\mathscr{C}$ has interior points, but $\Pi \mathscr{C}=\varnothing$. Then the intersection of some $n+2$ members of $\mathscr{C}$ is empty.

Proof. The lemma is trivially true for families consisting of $n+2$ sets. Assume, by induction, that $k \geqq n+2$, that the lemma is proved for all families consisting of $k$ sets, and that $\mathscr{C}=\left\{C_{i}: 0 \leqq i \leqq k\right\}$ satisfies $\Pi \mathscr{C}=\varnothing$. If the intersection of some $n+2$ or less members of $\mathscr{C}$ is empty, there is nothing to be proved; thus we may assume that all such intersections are nonempty. Consider the $k$-membered family $\mathscr{C}_{0}=\left\{C_{i}^{\prime}=C_{0} \cup C_{i}: 1 \leqq i \leqq k\right\}$. Because of Lemmas 1 and 2 the family $\mathscr{C}_{0}$ satisfies the assumptions of the present lemma. Since $\Pi \mathscr{C}_{0}=\varnothing$, the intersection of some $n+2$-membered subfamily of $\mathscr{C}_{0}$ is empty; assume $\bigcap_{i=1}^{n+2} C_{i}^{\prime}=\varnothing$. This is a contradiction to Helly's theorem on intersections of cells: on applying a stereographic projection of $S^{n}$ onto $E^{n}$, with center at a point of $S^{n}$ not in $C_{0}$, the sets $C_{i}^{\prime}, 1 \leqq i \leqq n+2$ yield a family of $n+2$ cells in $E^{n}$ which has an empty intersection although the intersection of any $n+1$ or less of them is, by Lemmas 1 and 2 , a cell and nonempty.

REMARK. Lemma 3 is easily seen to yield the finite case of Theorem 4 of Karlin and Shapley [8] which, in turn, implies results of Vincensini [14] and Molnár [10] for subsets of $S^{n}$ convex in yet another sense. (In [14] and [10] no precise definition of the term "convex" is given, but the results are valid only if "convex" means that the set is the intersection of open hemispheres.) The above proof of Lemma 3 is an adaptation of the reasoning in Molnár [10]. It would be nice to have an elementary proof (avoiding the use of Helly's topological theorem) for Lemma 3 and the theorems on convex sets or systems of inequalities related to it.

Lemma 4. Let $\mathscr{K}$ be a finite family of convex polyhedra in $E^{n}$ and let $1 \leqq k \leqq n$. If every intersection of $k$ members of $\mathscr{K}$ is of dimension $n$, but $\operatorname{dim} \Pi \mathscr{K}=n-k$, then there exist $k+1$ members of $\mathscr{K}$ such that their intersection is $(n-k)$-dimensional. 
Proof. Let $E^{n-k}$ be the subspace of $E^{n}$ generated by $\Pi$. , and let $E^{k}$ be an orthogonal complement of $E^{n-k}$ in $E^{n}$. Let $\mathscr{P}$ be the projection of $E^{n}$ onto $E^{k}$ along $E^{n-k}$. As easily seen, the family $\mathscr{K}^{\prime}=$ $\left\{K^{\prime}=\mathscr{P}(K): K \in \mathscr{K}\right\}$ has the following properties: (a) each $K^{\prime}$ is a $k$-dimensional polyhedron containing the origin 0 ; (b) the intersection of every $k$ sets $K^{\prime}$ is of dimension $k$; (c) $\Pi \mathscr{K}^{\prime}$ is the single point 0 . The subfamily $\mathscr{K}^{\prime \prime} \subset \mathscr{K}^{\prime}$ consisting of those members of $\mathscr{K}^{\prime}$ which contain 0 in their boundary, has the same properties. For each $K_{i}^{\prime \prime} \in \mathscr{K}^{\prime \prime}$ let $C_{i} \subset S^{k-1}$ be the set of all points $P \in S^{k-1}$ for which the open halfline through $P$ with end-point 0 intersects $K_{i}^{\prime \prime}$. Then the family $\mathscr{C}=$ $\left\{C_{i}\right\}$ consists of convex sets, such that the intersection of every $k$ of them has interior points while $\Pi \mathscr{C}=\varnothing$. By Lemma 3, with $n=k-1$, it follows that there exist $k+1$ sets $C_{i}$ with an empty intersection. The intersection of the corresponding sets $K_{i}^{\prime \prime}$ is then reduced to 0 , and that of the corresponding original ${ }^{\top} \operatorname{sets}^{\top} K_{i}$ is $\left(n^{n}-{ }^{r} k\right)$-dimensional.

3. We now return to the proof of assertion (iii) of the Theorem. We first prove $h(n, n-1)=n+1$ for $n \geqq 3$. Since obviously $h(n$, $n-1) \geqq n+1$, only the opposite inequality has to be proved. Let $\mathscr{K}$ be a finite family of convex polyhedra in $E^{n}$, such that each $n+1$ of them have an intersection of dimension $\geqq n-1$. If each such intersection has dimension $n$, then $\operatorname{dim} \Pi . \mathscr{K}=n$ since $h(n, n)=n+1$. In the other case, let $\mathscr{K}^{\prime} \subset \mathscr{K}$ be a minimal subfamily of $\mathscr{C}$ whose members have an intersection of dimension less than $n$. The family contains at most $n+1$ members and thus $\operatorname{dim} \Pi \mathscr{K}^{\prime}=n-1$. By Lemma 4, there exist $K_{1}, K_{2} \in \mathscr{K}^{\prime}$ such that $\operatorname{dim}\left(K_{1} \cap K_{2}\right)=n-1$. (The case that $\mathscr{K}^{\prime}$ contains a member of dimension $n-1$ is trivially reducible to $h(n-1, n-1)=n$.) Let $E^{n-1}$ be the subspace of $E^{n}$ spanned by $K_{1} \cap K_{2}$, and let $\mathscr{K}^{*}=\left\{K_{i}^{*}=K_{i} \cap E^{n-1}: K_{i} \in \mathscr{K}\right\}$. If every $n$ members of $\mathscr{K}^{*}$ have an $(n-1)$-dimensional intersection, we are through since $h(n-1, n-1)=n$. Assuming the other case, let $\mathscr{K}_{0}^{*}$ be a minimal subfamily of $\mathscr{K}^{*}$ such that its members have an intersection of dimension less than $n-1$. Let $\mathscr{K}_{0}$ be the subfamily of $\mathscr{K}$ consisting of those sets whose intersections with $E^{n-1}$ constitute $\mathscr{K}_{0}^{-*}$. Then $\mathscr{K}_{0}$ (and $\mathscr{K}_{0}^{*}$ ) must contain exactly $n$ members, since otherwise $\mathscr{K}_{0} \cup\left\{K_{1}, K_{2}\right\}$ would have at most $n+1$ members, with an intersection of dimension less than $n-1$. If $\operatorname{dim}\left(\Pi \mathscr{K}_{0} \cap E^{n-1}\right)=n-2$ a contradiction results : by Lemma 4 it follows that the intersection of some two members of $\mathscr{K}_{0}^{*}$ has dimension $n-2$, while the minimality of $\mathscr{K}_{0}^{*}$ then implies $n=2$; but $\mathrm{n} \geqq 3$ was assumed. Thus $\operatorname{dim}\left(\Pi_{0} \cap E^{n-1}\right) \leqq n-3$, and again a contradiction results: The sets $K_{1}$ and $K_{2}$, and hence the sets $K_{1} \cap \Pi \mathscr{K}_{0}$ and $K_{2} \cap \Pi \mathscr{K}_{0}$, are separated by $E^{n-1}$, and $\operatorname{dim}\left(K_{i} \cap \Pi \mathscr{K}_{0}\right)$ $\geqq n-1$. Therefore $E^{n-1}$ has to intersect $\Pi \mathscr{K}_{0}$ in a set of dimension 
$n-2$ at least. Thus a contradiction is reached in this case, too, and $h(n, n-1)=n+1$ is proved.

Next, we shall establish $h(n, k) \leqq 2 n-k$ for $1<k \leqq n-1$, using induction on $n$. In view of the above, we may assume $n \geqq k+2$. Starting, without loss of generality, with a family $\mathscr{T}$ of convex polyhedra of dimension $n$, each $2 n-k$ of which have an intersection of dimension $\geqq k$, the assertion is again trivial if the intersection of every $2 n-k$ members of $\%$ is $n$-dimensional. Let therefore $\mathscr{K}^{\prime}$ be a minimal subfamily of whose members have an intersection of dimension less than $n$. If. $\mathscr{T}^{\prime \prime}$ contains $m$ members then, by Lemma $4, r=\operatorname{dim}$ $\Pi$ I. ${ }^{\prime} \leqq n-m+1$ with $r \geqq k$. Applying the inductive assumption to the family $\mathscr{T}^{*}=\left\{K^{*}=K \cap E^{r}: K \in \mathscr{K}\right\}$, where $E^{r}$ is the subspace of $E^{n}$ spanned by $\Pi . \mathscr{K}^{\prime}$, the assertion $\operatorname{dim} \Pi . \mathscr{Y} \geqq k$ follows : if $r>k$, then $h(r, k) \leqq 2 r-k$ and thus $h(r, k)+m \leqq 2(n-m+1)-k+m \leqq 2 n-k$; therefore the intersection of every $h(r, k)$ members of . $\mathscr{K}^{*}$ contains the at least $k$-dimensional intersection of some $2 n-k$ members of $\%$; but $\Pi . \mathscr{K} \supset \Pi \mathscr{K}^{*}$. On the other hand, if $r=k$ then $h(k, k)=k+1$ and $h(k, k)+m \leqq n+2 \leqq 2 n-k$; since $k \leqq n-2$ was assumed, the result follows in this case as well.

Thus $h(n, k) \leqq 2 n-k$ is proved for all $n>k>1$. The converse inequality, and with it the theorem, may be established by easy examples.

REMARKs. It seems to be hard to extend the results of the present note to infinite families . $\mathscr{C}$. (Vincensini's assertion in [14] that $h(n, n)$ $=n+1$ holds for infinite families is incorrect.)

Professor F. A. Valentine has found alternative proofs for some of the results of the present paper, as well as related results.

\section{REFERENCES}

1. P. Alexandroff and H. Hopf, Topologie, Berlin, 1935.

2. L. L. Dines and N. H. McCoy, On linear inequalities, Trans. Royal Soc. Canada, Sect, III, 27 (1933), 37-70.

3. J. Favard, Sur les corps convexes, J. de Math., (9) 12 (1933), 219-282.

4. W. Gustin, On the interior of the convex hull of a Euclidean set, Bull. Amer. Math. Soc., 53 (1947), 299-301.

5. E. Helly, Ueber Mengen konvexer Körper mit gemeinschaftlichen Punkten, Jber. Deutsch. Math. Verein., 32 (1923), 175-176.

6. E. Helly, Ueber Systeme abgeschlossener Mengen mit gemeinschaftichen Punkten, Monatsh. Math., 37 (1930), 281-302.

7. A. Horn, Some generalizations of Helly's theorem on convex sets, Bull. Amer. Math. Soc., 55 (1949), 923-929.

8. S. Karlin and L. S. Shapley, Some applications of a theorem on convex functions, Ann of Math., 52 (1950), 148-153.

9. V. L. Klee, Jr., The critical set of a convex body, Amer. J. Math., 75 (1953), 178-188. 
10. J. Molnár, Ueber eine Uebertragung des Hellyschen Satzes in sphärische Räume, Acta Math. Acad. Sci. Hungar., 8 (1957), 315-318.

11. H. Rademacher and I. J. Schoenberg, Helly's theorem on convex domains and Tchebycheff's approximation problem, Canad. Math. J., 2 (1950), 245-256.

12. C. V. Robinson, Spherical theorems of Helly type and congruence indices of spherical caps, Amer. J. Math., 64 (1942), 260-272.

13. E. Steinitz, Bedingt konvergente Reihen und konvexe Systeme, I-II-III. J. reine angew. Math., 143 (1913), 128-175, 144 (1914), 1-40, 146 (1916), 1-52.

14. P. Vincensini, Figures convexes et variétés linćaires de l'espace Euclidean à $n$ dimensions, Bull. Sci. Math., 59 (1935), 163-174.

UNIVERSITY OF WASHINGTON 


\section{PACIFIC JOURNAL OF MATHEMATICS}

\section{EDITORS}

Ralph S. Phillips

Stanford University

Stanford, California

M. G. Arsove

University of Washington

Seattle 5, Washington
A. L. Whiteman

University of Southern Californla

Los Angeles 7, California

Lowell J. Paige

University of California

Los Angeles 24, California

\section{ASSOCIATE EDITORS}

E. F. BECKENBACH

D. DERRY

H. L. ROYDEN

E. G. STRAUS

T. M. CHERRY

M. OHTSUKA

E. SPANIER

F. WOLF

\section{SUPPORTING INSTITUTIONS}

UNIVERSITY OF BRITISH COLUMBIA

STANFORD UNIVERSITY

CALIFORNIA INSTITUTE OF TECHNOLOGY

UNIVERSITY OF CALIFORNIA

MONTANA STATE UNIVERSITY

UNIVERSITY OF TOKYO

UNIVERSITY OF UTAH

UNIVERSITY OF NEVADA

NEW MEXICO STATE UNIVERSITY

OREGON STATE UNIVERSITY

UNIVERSITY OF OREGON

OSAKA UNIVERSITY

WASHINGTON STATE UNIVERSITY

UNIVERSITY OF WASHINGTON

UNIVERSITY OF SOUTHERN CALIFORNIA

AMERICAN MATHEMATICAL SOCIETY CALIFORNIA RESEARCH CORPORATION SPACE TECHNOLOGY LABORATORIES NAVAL ORDNANCE TEST STATION 


\section{Pacific Journal of Mathematics}

\section{Vol. 12, No. $1 \quad$ January, 1962}

Jonathan L. Alperin, Groups with finitely many automorphisms $\ldots \ldots \ldots \ldots \ldots \ldots \ldots \ldots$

Martin Arthur Arkowitz, The generalized Whitehead product ................ 7

John D. Baum, Instability and asymptoticity in toplogical dynamics . . . . . . . . . . 25

William Aaron Beyer, Hausdorff dimension of level sets of some Rademacher series .... $\quad 35$

Frank Herbert Brownell, III, A note on Cook's wave-matrix theorem . . . . . . . . . . . . . 47

Gulbank D. Chakerian, An inequality for closed space curves ................. 53

Inge Futtrup Christensen, Some further extensions of a theorem of Marcinkiewicz ....... 59

Charles Vernon Coffman, Linear differential equations on cones in Banach spaces . . . . . 69

Eckford Cohen, Arithmetical notes. III. Certain equally distributed sets of integers . . . . . 77

John Irving Derr and Angus E. Taylor, Operators of meromorphic type with multiple poles

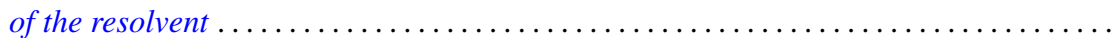

Jacob Feldman, On measurability of stochastic processes in products space .............

Robert S. Freeman, Closed extensions of the Laplace operator determined by a general class of boundary conditions, for unbounded regions ......................

Robert E. Fullerton, Geometric structure of absolute basis systems in a linear topological

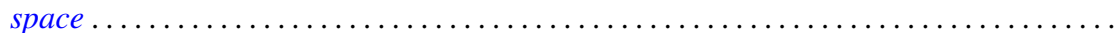

Dieter Gaier, On conformal mapping of nearly circular regions

Andrew Mattei Gleason and Hassler Whitney, The extension of linear functionals defined

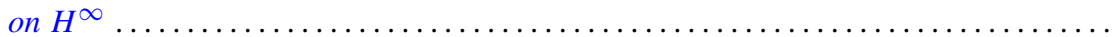

Seymour Goldberg, Closed linear operators and associated continuous linear

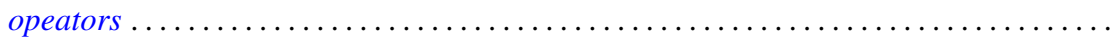

Basil Gordon, Aviezri Siegmund Fraenkel and Ernst Gabor Straus, On the determination of sets by the sets of sums of a certain order

Branko Grünbaum, The dimension of intersections of convex sets. .

Paul Daniel Hill, On the number of pure subgroups

Robert Peter Holten, Generalized Goursat problem . .

Alfred Horn, Eigenvalues of sums of Hermitian matrices ...........

Henry C. Howard, Oscillation and nonoscillation criteria for

$$
y^{\prime \prime}(x)+f(y(x)) p(x)=0
$$

Taqdir Husain, $S$-spaces and the open mapping theorem ...

Richard Eugene Isaac, Markov processes and unique stationary probability measures ...

John Rolfe Isbell, Supercomplete spaces ....................

John Rolfe Isbell, On finite-dimensional uniform spaces. II .........

N. Jacobson, A note on automorphisms of Lie algebras ..............

Antoni A. Kosinski, A theorem on families of acyclic sets and its applications

Marvin David Marcus and H. Minc, The invariance of symmetric functions of singular values...

Ralph David McWilliams, A note on weak sequential convergence.

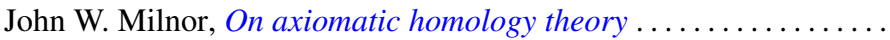

Victor Julius Mizel and Malempati Madhusudana Rao, Nonsymmetric projections in

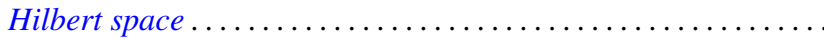

Calvin Cooper Moore, On the Frobenius reciprocity theorem for locally compact

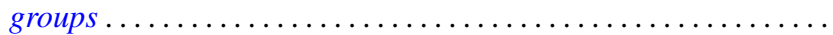

Donald J. Newman, The Gibbs phenomenon for Hausdorff means . 